\title{
What can People Risk Attitude Tell us about People Preference for Multimedia Quality?
}

\begin{abstract}
Multimedia content that is accessible through mobile devices has a larger size than other types of content (e.g. text, images). This may lead to higher prices for accessing the content via mobile devices, as mobile operators are capping mobile data billing plans in an effort to increase their revenues and prevent congestion (Sen et al., 2013). This poses problems for the users that are not willing/do not afford to pay the required price but still want to use multimedia content through the mobile networks. A price reduction for the user, as well as minimising bandwidth consumption can be obtained as a trade-off in multimedia quality. However, as previous research shows, not all people are willing to trade-off quality for a lower price; therefore, there is no straightforward approach to this problem. In this context, this paper presents a model of user willingness to pay for multimedia content quality as a function of the user risk attitude with the aim to provide personalised content depending on the user willingness to trade-off price for multimedia content quality. A stereotypical approach is used where users are divided in two groups: risk averse and risk seekers. This approach is validated through a series of six studies. The results show that the risk adverse users prefer a lower multimedia quality than the risk seekers with the aim to reduce delivery cost.
\end{abstract}

Keywords: user models, user studies, adaptation and personalisation, user characteristics, ubiquitous and mobile computing design and evaluation, user risk attitude, 


\section{Introduction}

As mobile device penetration increases, mobile phones are becoming almost a ubiquitous presence in people's life. However, the high cost of mobile data transmission over wireless networks (Albert 2012) and capped billing plans (Bode 2012) are some of the problems mobile Internet users face. Additionally, although some of the mobile network operators have previously offered flat rate billing plans, this has proved unsustainable (Rio et al. 2012), and the results have led to mobile data plans that are mostly capped (Bode 2012). This pricing model is likely to continue to persist as mobile data traffic increases dramatically (Traverso et al., 2012, Trestian et al. 2012, LTE 2012). With that in mind, not even the deployment of high-speed networks such as Long Term Evolution (LTE) will make uncapped plans sustainable (LTE 2012).

This problem is further on aggravated when multimedia content, such as video, is used, as this content type is larger in size. This can lead to a higher price that needs to be paid by the consumer, as capped billing plans are limited to a certain amount of data and once this quantity is exceeded, a higher price has to be paid, another data bundle needs to be acquired or the bandwidth is throttled.

On the other side, it has been shown that not all users are affected by the high price, and that some people are not willing to pay that much and are happy to trade-off for multimedia quality (Molnar and Muntean 2010, Sackl et al. 2012). Decreasing the quality of multimedia content in a controlled manner has been shown to have positive results in reducing the multimedia access cost and it does not necessarily negatively affects the multimedia perceived quality or the capacity to assimilate information from the multimedia content (Ghinea and Chen 2008, Molnar and Muntean 2011, Molnar and Muntean, 2013). In this context, there is a need for a solution to reduce the cost for mobile data users that cannot afford, or are not willing to pay extra. This research paper uses consumer behaviour theory, more specifically the user risk attitude to model user preferences for multimedia quality when a certain price needs to be paid. A stereotypical approach is followed, in which the users are classified in either risk averse (willing to trade-off for multimedia quality) or risk seekers (willing to pay for the multimedia quality). Based on this model user receives an adapted multimedia content depending on which category s/he is. The proposed model is validated through a series of six case studies. 
In doing so this article adds to the state of the art by providing a novel way to model the user preferences for multimedia quality based on their attitude towards risk, age, and gender. This research also validates the proposed model and shows that the participants who are risk averse are less likely to prefer a higher multimedia quality when they have to pay for its delivery and the risk seekers are more likely to stick with a higher multimedia quality despite the price they have to pay.

The paper is organised as follows. The second section introduces consumer behaviour theory and where the user risk attitude stands in this field, as well as previous research on how people use mobile data billing plans. The third section presents the proposed user risk attitude model. The forth section presents the evaluation of the proposed model. The fifth section discusses the results and how they can be used in a broader context.

\section{Consumer Behaviour}

The behavioural economics area is a branch of economics that integrates psychology with neo-classical economics. It identifies ways in which people's behaviour is different from the standard model based on which people act to maximise their pay off. Behavioural economics is concerned mostly with the bounds of rationality and what effects the emotional, cognitive, and social factors have on human decisions directly and on the market indirectly. Among the dispositions that drive economic decisions is the human attitude towards risk. Risk is an integral part of decision making (Nielsen et al. 2013). It is considered "the pivotal element in consumer behaviour" (Taylor 1974) and a central element to economics and finances (Bucciol and Zarri, 2013). It is most often associated with uncertainty (e.g. missing information - making decisions about an unfamiliar brand, however "full information" contexts do not imply missing uncertainty (Bruke 2010)).

\section{Risk Attitude}

It has been found that the risk attitude has a great impact on many of the decisions that a person makes such as those involved in stock investment, educational attainment, ownership of a home and occupational choices 
(Dohmen et al. 2013). Understanding people's attitude towards risk is linked to predicting consumer behaviour (Dohmen et al. 2011). Based on their attitudes towards risk, people can be classified into:

- $\quad$ Risk averse - they prefer not to take on risks;

- $\quad$ Risk neutral - who are neutral to risk;

- $\quad$ Risk seekers -they love risk.

Sometimes, only the first and the last categories are being used, risk neutral individuals being included in none of the previous two categories. This depends on the relevance of the categories for the experiment, or on whether or not the method used is able to determine whom the risk neutral people are. Experimental studies involving lottery and hypothetical questions are typically able to determine a risk neutral person. Studies in which people are asked to assess on a scale their attitude towards risk in general or in different contexts, cannot determine where on the given scale the risk neutral persons are. The last ones were used to determine the user attitude towards risk across different contexts such as health, financial matters, and career, in order to predict economic behaviour or to explain different decisions people take (Hammitt and Haninger 2010, Dohmen et al. 2011, Niederle and Vesterlund 2007).

Concerning the distribution of people's risk attitude, studies have shown that people are mostly risk averse, and this seems to be maintained across cultures (Dohmen et al. 2011, Harrison et al. 2007, Holt and Laury 2002, Ding et al. 2010). The critique for risk theory is that it does not explain user preference for flat rate pricing when they can choose between a flat rate type of tariff and pay-per-use. This phenomenon has been called "flat-rate bias" (Train 1991). Lambrecht and Skiera (2006) found that over 50\% of the customers of a German Internet provider used a flat rate service, when a measured one would have been more suitable for them in terms of monetary cost. Studies that document bias towards flat rate tariffs are also found in the mobile telephony area (Gerpott 2009, Mitomo et al. 2009). Gerpott (2009) argued that because people have difficulties in estimating how much they will spend could explain this bias. In this case, they tend to overestimate the amount they spend. Based on their erroneous assumptions, they believe that a flat-rate tariff will be the most suitable solution for them. Other studies on mobile telephony also show that people do not know how to estimate the cost associated 
with mobile data access for different billing plans (Isomursu et al. 2007, Roto et al. 2006). Roto et al. (2006) shows that the mobile phone Internet subscribers that use a mobile data billing plan, are confused about how much money they do spend.

As indirect survey approaches for willingness to pay estimation are considered the most suitable in real-world applications "because they usually exhibit both higher internal and external validity" (Breidert et al. 2006), user risk attitude is used in our research to model the user willingness to pay for accessing multimedia content. In this context, risk adverse users are willing to trade off multimedia quality, whereas the risk seekers are willing to pay for the quality. The fact that risk adverse users are less willing to pay in risky situations is well documented in different previous studies (Brachinger et al. 1997, Weber 1999). Moreover, Markowitz (1959) has modelled the people willingness to pay as a function of risk, however to the best of our knowledge it has not been yet used to assess how people will prefer to pay for the multimedia quality when monetary cost is involved. As risk attitude has been used in various studies, it is relatively easy to assess, and it has been shown to be stable across different domains (Dohman et al. 2011, Guiso, et al., 2013). This research paper proposes to model the user risk attitude in order to determine the people willingness to pay for multimedia quality. The aim is to reduce the multimedia delivery cost for the users who are not willing to pay a full price.

\section{Risk Attitude Assessment}

There are several methods to elicit user risk attitude (Nielsen et al. 2013), which can be broadly divided in experimental studies or questionnaires. There is no standard method to assess risk attitude and there is a gap in the research assessing which method is more suitable (Nielsen et al. 2013). During experimental studies, people are asked to play a lottery with real money at stake an, based on their choices the risk attitude is assessed. The main advantage of using experiments is that they offer a compatible incentive for measuring the risk attitude (Eckel and Grossman 2007). However, experiments are usually lengthy and they necessitate real money that makes them costly. A cheaper alternative is to use questionnaires. The main advantage of the questionnaire is that it is a direct method as opposed to experiments where behavioural parameters have to be taken into account 
(Dohmen et al. 2005). There are two ways to determine the user's attitude towards risk through questionnaires: either by using the so-called lottery question (Nunes 2000) or user self-assessment (Dohmen et al. 2011). Based on the user answer to any of two questions, the person is categorised.

The most common method is the hypothetical lottery question, where the subjects are presented with a set of lottery like choices and are asked to select the choice they prefer. An example of a lottery question is:

"Imagine you are at a community fair. You have just won a throwing game and are entitled to claim a $\$ 40$ prize. The operator of the game offers a second follow up game with the prize money. In this game, you will spin a wheel with two colors, yellow and green. You final prize depends on which color an arrow on the side is pointing to when the wheel stops spinning. If the pointer is on yellow, you win \$60. If it comes up green you get only \$20. At what settings of the odds to win (percentage on the wheel that is yellow) would you agree to play the follow up game? Answers can range from 1\% to 100\%" (Nunes 2000).

Using the hypothetical lottery question is cheaper than the experimental study because it does not involve real money. However, even though a hypothetical question is a strong predictor for financial domains, they might not predict the actual behaviour in different contexts (Dohmen et al. 2011).

More recent studies have found that asking users to rate themselves leads to a better prediction of the user attitude across various contexts such as financial, career, health, car driving, sports and leisure (Caliendo et al. 2009, Dohmen et al. 2011, Jaeger et al. 2010). The method where people are asked to rate their willingness to take risk in general is called the general risk question (Dohmen et al. 2011). It has been shown to be "the only measure to predict all of the behaviours", being "the best all-around measure" (Dohmen et al. 2005). Moreover, recent studies comparing different risk assessment methods concluded that the self-assessment scale is easy to administer, and comprehend and it is easily adapted to different scenarios (Nielsen et al. 2013). The general risk question maps to the actual choices from the lottery experiment (Dohmen et al. 2011) and has the potential to incorporate both risk preferences and risk perception (Dohmen et al. 2005). The general risk question as used in Dohmen et al. (2011) is "How willing are you to take risks in general". A scale from 0 to 10 is given for the 
subjects to rate their willingness, where 0 means, "not at all willing to take risks" and 10 means "very willing to take risks" (Dohmen et al. 2011).

The general risk question was initially tested with a representative sample of 22,000 people of German nationality. The sample was also answering the hypothetical lottery questions. Moreover, risk attitudes across different contexts (holding stocks, sport, health, and self-employment) were also assessed (Dohmen et al. 2011). The study shows that the general risk question is a better measure to predict the risk attitude across different contexts than the hypothetical lottery question, indicating that it is a reliable proxy for risk behaviour across domains. Afterwards, the results were validated with experimental studies on 450 people, chosen in the same way as the initial sample (Dohmen et al. 2011). Since then, different other studies have successfully used the general risk question (Caliendo et al. 2009, Jaege et al. 2010, Grund and Sliwka 2010, Hardeweg et al. 2013). Although different categories of users have been defined, usually users are divided either in two categories: risk averse and risk seekers, or in three by separating risk neutrals from the previous two ones.

Deciding which method to use in assessing the risk aversion depends on the scope of the study. Experimental studies are generally considered the best, however, they are hard and costly to organise for a large sample (Falk et al. 2013). The questionnaire could easily cover a bigger sample, and it was shown to provide accurate results as well. This research uses the questionnaire, as it is easier to assess and model by a computer system. Among the methods presented, the general risk question was used. Table 1 justifies our decision of selecting the general risk question by presenting its advantages as compared with the previous two assessment methods. The first column indicates the advantages of using the general risk question compared to experimental studies, whereas the second column presents the advantages of this technique compared to the hypothetical lottery question. As it can be noticed from Table 1, the general risk question is easier to administer especially with online environments. It also offers several advantages compared to the hypothetical lottery questions. Even though it is a recently used metric, it has already been successfully used in several studies (Caliendo et al. 2009, Grund and Sliwka 2010, Jaeger et al. 2010) making it a very good candidate for use in assessing the user attitude towards risk in online environments. 
Table 1. Advantages of Using the General Risk Question Compared to Experimental Studies and the Hypothetical Lottery Question

\begin{tabular}{ll}
\hline General Risk Question vs. Experimental Studies & General Risk Question vs. Hypothetical Lottery Question \\
\hline With the general risk question there is no need for an & The general risk question offers better prediction across different \\
experimental study every time a new user joins the system as an & domains (Dohmen et al. 2011) \\
experimental study will be required to determine the user risk & The general risk question has test-re-test stability, which is not \\
attitude & the case with the lottery question (Lönnqvist 2011) \\
The general risk question is cheaper in terms of money since it & The general risk question is free from framing effects and \\
does not involve bets with money at stake (Falk et al. 2013) & numeracy demands characteristics for lottery question (Borghans \\
The general risk question is less time consuming; it is faster to & et al. 2008) \\
answer a question than to participate in a whole experiment & \\
(Falk et al. 2013)
\end{tabular}

\section{Impact of Mobile Data Plans on User Behaviour}

There are various mobile data billing plans on the market. Among them, bundle/capped billing plans are predominant on the European market (Molnar and Muntean 2013) and USA (Vallina-Rodriguez et al. 2012). As opposed to unlimited billing plans, capped billing plans offer users a limited amount of data. The consequences of exceeding data consumption vary from paying more for the exceeding data, paying for a new bundle, or having the bandwidth limited. These types of billing plans are commonly used for mobile Internet access, and sometimes for home Internet connections (Chetty et al. 2012). Despite their popularity, few research studies have considered user perception when these billing plans are used, research focusing mostly at using these billing plans as a means of managing network congestion and technical aspects involved (Chetty et al. 2012).

Among the studies that have focused on how mobile data billing plans affect Internet usage, one can count Chetty et al. (2012), Roto et al. (2006), Middleton and Shang (2008), Isomursu et al., (2007), Molnar and Muntean (2010). These studies explored at what effects different mobile data billing plans have on mobile user behaviour. All these studies report that the user behaviour changes according to the Internet billing plan used.

Moreover, users reported problems with the high delivery cost (Chetty et al. 2012). Other studies assessed how 
people's choice of different multimedia quality are affected by capped mobile data billing plans showing that people are willing to watch a lower quality multimedia clip when they are aware that they have to pay more for a higher quality (Molnar and Muntean 2010). However, this pattern was not followed by all the participants, some being willing to pay for the quality even when the price was relatively high (Molnar and Muntean 2010).

This paper proposes to use the user risk attitude as a means of determining the people willingness to pay for multimedia quality. A user risk attitude model is proposed and validations tests were performed through different case studies involving accessing multimedia content at different quality levels, when different billing plans are used.

\section{Modelling User Risk Attitude}

As the user risk attitude can predict economic behaviour (Dohmen et al. 2011), and has been previously used to model the willingness to pay (Brachinger et al. 1997, Weber 1999, Markowitz 1959), this research proposes a novel user risk attitude model that takes into account the user self-assessment regarding his/her attitude towards risk, as well as age and gender.

\section{User Risk Attitude}

User self-assessment based on the general risk question was previously used in various research studies to determine the user risk attitude and it has been shown to be an accurate measure (Dohmen et al. 2011). The general risk question can be asked during the user registration process, or at certain moments considered appropriate when the user uses the system. The general risk question asks users to assess their attitude towards risk on a 0 (risk averse) to 10 (fully prepared to take risks) scale. Users who pick a value between 0 and 5 (inclusive) are classified as risk averse, and the ones that select a value higher than 5 are classified as risk seekers (Dohmen et al. 2011). For example, a user who selects the value 3 is considered risk averse, and the user who selects the value of 7 is considered a risk seeker. 
The general risk question can be formulated as the one used in the Socio-Economic Panel (Soziooekonomische Panel - SOEP) (SOEP v26) and later on in different research studies such as Dohmen et al. (2011). SOEP is a survey performed by the German Institute. It is a longitudinal research study, the survey taking place each year since 1984 and used for economic research. The general risk question, as used in this survey is presented in Figure. 1:

“How do you see yourself:

Are you generally a person who is fully prepared to take risks or do you try to avoid taking risks?

Please tick a box on the scale, where the 0 means "risk averse" and the value 10 means "fully prepared to take risks".

You can use the values in between to make your estimate."

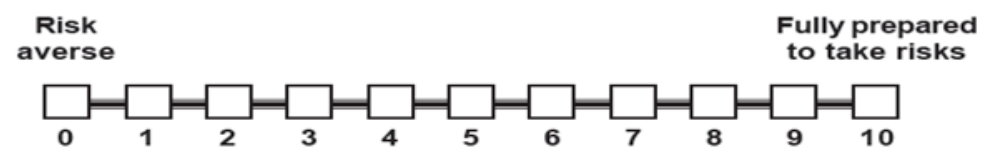

Fig. 1 User risk attitude as assessed by SEOP study (SOEP v26)

\section{Age and Gender}

Previous studies have shown that the risk attitude varies across gender and age (Dohmen et al. 2011, Dohmen and Falk 2010) -. How user aversion differs based on age and gender was analysed in this research using the results of the SOEP survey administered to 20,869 people.

SEOP survey subjects were asked to provide, among others, information about their gender, the year when they were born, and to answer the general risk question. The subjects who filled in the survey had ages varying from 17 up to 100 years old. Subjects with an age less than 18 (the sample contained only females) and subjects whose age is over 90 (due to the low number of people- e.g. there were only 3 people that were 96 years old) were eliminated. SOEP records that did not provide information about people's gender were also eliminated. As a result, a total of 20,686 people were used in the analysis. There were 10,820 (52\%) women, and 9, 866 (48\%) 
men. $20 \%$ of the subjects were between 18 and 30 years old, $42 \%$ were 31 to 50 years old, $22 \%$ were 51 to 70 years old and $16 \%$ were 71 to 90 years old.

Based on the performed analysis on the SOEP data set, RVAgeGender is proposed to compute the user risk value based on age and gender (Equation 1). For a given person, RVAgeGender is the sum of probabilities of having a certain risk value $\mathrm{i}$ for a certain gender and certain age (ProbabilityRVi), multiplied by the Risk Value $R V i$, where $i$ has a value from 0 up to 10 (a value on the general risk question scale).

$$
R V_{\text {AgeGender }}=\sum_{i=0}^{10} R V_{i} * \text { Probability } R V_{i}
$$

For example, for a 24 year old female, the percentage of subjects that have been assigned a particular risk value is presented in Table 2 . The first column represents the 0 to 10 risk value range, and the second column the percentage of 24 year old females that were found for each risk value. $R V_{i}$ represents a particular risk value as presented in the first row of Table 2. ProbabilityR $V_{\mathrm{i}}$ represents the percentage of people of a certain age and gender that have selected, $R V_{i}$. Therefore $R V_{24 F e m a l e}$ is 4.91 . This value is combined with the subjects' answer to the general risk question to compute the user's risk attitude, RV.

$$
\begin{gathered}
\mathrm{RV}_{24 \text { Female }}=0 * 0.021+1 * 0.0035+2 * 0.1049+3 * 0.1119+4 * 0.0909+5 * 0.2308+6 * \\
* 0.1329+7 * 0.1678+8 * 0.0839+9 * 0.007+10 * 0.014 \\
\mathrm{RV}_{\text {24Female }}=4.91
\end{gathered}
$$


Table 2. Percentage of subjects that have selected a certain risk value in the SOEP survey

\begin{tabular}{|c|c|c|c|c|c|c|c|c|c|c|}
\hline Sex & \multicolumn{5}{|c|}{ Female } & \multicolumn{5}{|c|}{ Male } \\
\hline Age & 24 & 34 & 55 & 75 & 86 & 24 & 34 & 55 & 75 & 86 \\
\hline $\mathrm{RV}$ & & & & & & & & & & \\
\hline 0 & $2.10 \%$ & $3.25 \%$ & $8.37 \%$ & $10.28 \%$ & $13.33 \%$ & $4.27 \%$ & $5.69 \%$ & $14.29 \%$ & $23.42 \%$ & $37.84 \%$ \\
\hline 1 & $3.50 \%$ & $6.50 \%$ & $5.73 \%$ & $9.35 \%$ & $26.67 \%$ & $4.27 \%$ & $6.50 \%$ & $10.71 \%$ & $12.61 \%$ & $18.92 \%$ \\
\hline 2 & $10.49 \%$ & $19.51 \%$ & $11.45 \%$ & $23.36 \%$ & $3.33 \%$ & $12.82 \%$ & $11.39 \%$ & $18.57 \%$ & $15.32 \%$ & $21.62 \%$ \\
\hline 3 & $11.19 \%$ & $20.33 \%$ & $16.30 \%$ & $19.63 \%$ & $13.33 \%$ & $13.68 \%$ & $14.63 \%$ & $9.29 \%$ & $19.82 \%$ & $8.11 \%$ \\
\hline 4 & $9.09 \%$ & $11.38 \%$ & $15.86 \%$ & $10.28 \%$ & $10 \%$ & $11.97 \%$ & $12.20 \%$ & $12.14 \%$ & $5.41 \%$ & $2.70 \%$ \\
\hline 5 & $23.08 \%$ & $15.45 \%$ & $22.47 \%$ & $17.76 \%$ & $16.67 \%$ & $18.80 \%$ & $21.95 \%$ & $15.71 \%$ & $9.91 \%$ & $2.70 \%$ \\
\hline 6 & $13.29 \%$ & $5.69 \%$ & $10.13 \%$ & $5.61 \%$ & $10 \%$ & $13.68 \%$ & $15.45 \%$ & $7.86 \%$ & $9.01 \%$ & $0 \%$ \\
\hline 7 & $16.78 \%$ & $12.20 \%$ & $6.61 \%$ & $1.87 \%$ & $6.67 \%$ & $14.53 \%$ & $8.13 \%$ & $5.71 \%$ & $0.90 \%$ & $5.41 \%$ \\
\hline 8 & $8.39 \%$ & $5.69 \%$ & $1.76 \%$ & $0.93 \%$ & $0 \%$ & $5.13 \%$ & $2.44 \%$ & $5 \%$ & $2.70 \%$ & $2.70 \%$ \\
\hline 9 & $0.70 \%$ & $0 \%$ & $0.88 \%$ & $0.93 \%$ & $0 \%$ & $0.85 \%$ & $0.81 \%$ & $0.71 \%$ & $0.90 \%$ & $0 \%$ \\
\hline 10 & $1.40 \%$ & $0 \%$ & $0.44 \%$ & $0 \%$ & $0 \%$ & $0 \%$ & $0.81 \%$ & $0 \%$ & $0 \%$ & $0 \%$ \\
\hline
\end{tabular}

\section{User Risk Attitude Value}

The proposed user risk attitude formula $(R V)$, used to model the user attitude, has two parameters: one that considers the user self-assessment (RVGeneralRiskQuestion) based on the persons' answer to the general risk question and another parameter that considers a more general the user risk attitude based on statistical analysis on gender and age (RVAgeGender), as presented in Equation 2.

$$
R V=w_{1} * \mathrm{RV}_{\text {GeneralRiskQuestion }}+w_{2} * R V_{\text {AgeGender }}, \text { where } w_{1}+w_{2}=1(2)
$$

The value of the first parameter, RVGeneralRiskQuestion, is computed based on the answer given by the user to answering the general risk question. The second parameter, RVAgeGender is computed based on the analysis performed on the SOEP data set as described in the third section. Both RVGeneralRiskQuestion and RVAgeGender return a value between 0 and 10 , as will the $\mathrm{RV}$ formula. If the result of the $\mathrm{RV}$ formula is a value between zero and less than or equal to 5 , the user is classified as a risk seeker. If the value is greater than 5 as risk 
averse. In our research, for easier computation, we consider both $\mathrm{w}_{1}$ and $\mathrm{w}_{2}$ equal. However, different weights can be chosen for the two factors.

For example, if a 24 years old female will select a risk value equal with 7 at the general risk question, and considering $\mathrm{w}_{1}$ and $\mathrm{w}_{2}$ equal, then $\mathrm{RV}$ is 5.96 , which is greater than 5 hence the person is a risk seeker.

$$
\begin{gathered}
\mathrm{RV}=0.5 * 7+0.5 * 4.91 \\
\mathrm{RV}=5.96
\end{gathered}
$$

\section{Experimental Study}

The aim of the experimental study was to validate the proposed user risk attitude model in the context of delivering personalised multimedia content. Based on this model, the user can be either risk seeker or risk averse. In this context, the risk adverse people would prefer a lower multimedia quality and to pay a lower cost, while the risk seekers would prefer to pay for the quality.

\section{Set-Up Conditions}

Six scenarios were designed based on existing mobile data billing plans. For each scenario, a multimedia clip encoded at five different quality levels was used. Each multimedia version would imply a different consequence for the subject (e.g. the higher the quality, the higher the price to be paid or the more data from the acquired bundle is consumed). The study took place in a controlled environment, the subjects not being able to speak one with each other. The study set-up followed the set-up recommendations for studies in which the subjects are asked to assess video quality as described in (ITU-T P.910, 2008). Subjects were asked to select the multimedia clip version they prefer based on the given scenario. They were asked to see each version of the clip at least once, and they could return to any version of the multimedia clip as many times as they wanted. The duration of the study varied between 20 minutes to one hour.

76 subjects took part in this study on a volunteer basis. To recruit the participants posters were printed and placed in common areas, as well as emails were sent to the students and staff members in two of the higher education institutions in Ireland. At the end of the study the participants took part in a drawing where prizes were 
given. The participants were of different nationalities. The division based on gender was: $26 \%$ females and $74 \%$ males and their age varied from 19 to 57 years old. $57 \%$ of the subjects are younger than 30 . The average participants' age is 31 years old, and the standard deviation is 9.45 . The participants were asked at the beginning of the study to provide their age, gender, and to answer the general risk question. The participants taking part in the study were classified in two categories, risk averse and risk seekers, based on the computed value of the RV formula presented in the third section.

The subjects' risk attitude division was: $36 \%$ of the subjects were risk averse and $64 \%$ risk seekers. The high number of risk seeking subjects can be explained by the fact that many of the subjects have a high level of education (e.g. postdoctoral researchers). This category is known to have a positive attitude towards risk (Donkers et al. 2001, Rosen et al. 2003).

The subjects were provided with a Google Nexus smartphone. A smartphone was selected for the study due to the fact that these mobile phones would soon be dominant on the market (Chu 2012). An Android smartphone was selected due to the fact that it is the most common OS currently on the market (Lance 2014). The smartphone resolution was selected based on a study we have performed regarding the most common resolutions among smartphones (Molnar \& Muntean 2013). The study shows that 480 x 800 is the most common resolution (35\%) and $320 \times 480$ is the second common resolution (25\%) among the surveyed smartphones (Molnar \& Muntean 2013).

For the purpose of the study, Google Nexus, a smartphone with a resolution of $480 \times 800$ was selected. The device has the following characteristics: a resolution of $480 \times 800$, 3.7" screen size, it supports various wireless networks (2G, 3G, 3.5G, Wi-Fi), multimedia formats (e.g. H.264, H.263, MP4), 512MB internal memory and $1 \mathrm{GHz} \mathrm{CPU}$.

\section{Multimedia Clip}

As the type of dynamicity presented in a multimedia clip, may affect the perceived quality, a multimedia clip that contains a variety of scenes varying from low to high dynamicity was selected. The multimedia clip was 
downloaded from iTunes $U$. The clip presents an introduction on the importance of telescopes for learning more about the universe. It also introduces Chandra, the most powerful telescope ever made in 1999. The clip is 1 minute and 44 seconds long. It has a resolution of $540 \times 960$, a bit rate value of $3654 \mathrm{kbps}$, and the encoding format is MPEG-4 ACV/H.264. The clip was selected to be of high quality, because different encoding versions of the same multimedia clip were necessary to be created for the experimental study.

The multimedia was encoded at five different quality levels used for testing. Table 3 presents the encoding settings that were used. The first column presents the version of the multimedia clip. The second column shows the resolution and the third the bit rate at which the multimedia clip was encoded. The last column presents the size of the clip.

The resolutions of the five versions were selected so that they match the two most used resolutions of smartphones found in (Molnar \& Muntean, 2013) one of them being the actual device resolution. A smaller resolution may be used when multimedia adaptation is performed, for example when a smaller size multimedia clip is necessary due to wireless network constraints (Wowza n.d.; Apple 2010). The multimedia bit rate values were selected to match the intervals recommended for multimedia adaptation by different organizations, such as Wowza and Apple that provide adaptive multimedia streaming (Wowza n.d., Apple 2010) or organisations that provide guidelines for multimedia delivery such as the Australian Mobile Learning Standard (MLS 2010).

For a certain resolution, the bit rate thresholds for the multimedia clip are established based on these recommendations. For a resolution of $800 \times 480$, the bit rate value was recommended to be between 600 and $1000 \mathrm{kbps}$, and for $480 \times 320$ between 150 and $550 \mathrm{kbps}$. The second resolution is used when the bandwidth does not support the delivery of the first resolution without losses. This could be the case of a $3 \mathrm{G}$ network where 384 kbps is the medium coverage for pedestrian use (IMT 2000 (ITU-T 2000) as cited by (Jeff 2008)). In this case, the second resolution has to be used. 
Table 3. Multimedia Version Characteristics

\begin{tabular}{cccc}
\hline Version & Multimedia Clip Resolution & Multimedia Clip Bit Rate (kbps) & Multimedia Size (MB) \\
\hline 5 & $800 \times 480$ & 1000 & 14 \\
4 & $800 \times 480$ & 600 & 5.15 \\
3 & $480 \times 320$ & 550 & 3.46 \\
2 & $480 \times 320$ & 350 & 5.99 \\
1 & $480 \times 320$ & 150 & 3.65 \\
\hline
\end{tabular}

\section{Billing Plans}

Various mobile data billing plans are on the market such as: bundle/capped based, time based, data based, and flat rate. A time based billing plan requires the user to pay for the time s/he is using the Internet connection. A data based billing plan requires the user to pay for the amount of data consumed. With a flat rate billing plan the user has unlimited Internet access for which s/he pays a fee.

To decide which billing plans would be used for the experimental study, we used the results of the survey containing the most common billing plans in Europe presented in Molnar \& Muntean (2013). Both pre-paid (pay as you go) and contract based (billed paid, post-paid) plans were considered of importance for this study. A prepaid billing plan also requires the customer to pay in advance for the provided service. A contract based billing plan requires the customer to pay for the service at the end of a given period, typically a month. The survey results showed that bundle/capped based billing plans are the most used billing plans both for contract and prepaid plans (see Table 4).

Table 4. Billing Plans Analysis Results

\begin{tabular}{ccccc}
\hline Billing Plan Type & Capped/Bundle based & Data based & Flat Rate & \\
\hline Pre-paid & $85 \%$ & $4 \%$ & $4 \%$ & $7 \%$ \\
Contract based & $98 \%$ & $0 \%$ & $2 \%$ & $0 \%$ \\
\hline
\end{tabular}




\section{Evaluation Results}

A scenario based experimental study was used to validate the proposed user risk attitude model. The subjects were given six hypothetical scenarios. The last five scenarios involved different billing plans that exist on the market and the subjects were asked to select the preferred multimedia version in different circumstances. Three bundle/capped based billing plans were selected, as this type of billing plan is currently predominant on the market. Among the bundle based billing plans, we selected three of them with the aim of covering the two cases in which the user can find himself once the amount of data contained in the bundle is exceeded (pay for the exceeding quantity or the bandwidth is limited) and also to reflect the difference in price changes that exist on the market. These were billing plans in use at the time when the study was performed.

Billing plan 1.

Pay extra when exceeding the data quantity included in the bundle: A bundle based billing plan, where the user pays for $50 \mathrm{MB}$ of data per day. If the quantity is exceeded, the user has to pay an extra l€ per MB consumed.

- Scenario 2, and Scenario 3 make use of this billing plan

Billing plan 2.

Pay extra when exceeding the data quantity included in the bundle: A bundle based billing plan, where the user pays for $500 M B$ per month. If the quantity is exceeded, the user has to pay an extra $2 c$ per $M B$ consumed.

- Scenario 4 and Scenario 5 make use of this billing plan

Billing plan 3.

The bandwidth is limited: A bundle billing plan where the bandwidth is limited to 64 kbps after exceeding the $300 M B$ included in the data plan.

- Scenario 6 make use of this billing plan

The subjects were also provided with information regarding the size of multimedia clips version. They were also allowed to see the clips how many times they wanted, and to replay certain sections if they wanted to. They 
were allowed as much time as they needed to make a decision. They were asked to indicate their preferred multimedia quality among the five versions of a multimedia clip presented. If they preferred any version, they had the option to choose Any of them, but they could not select more than one option as the preferred one. The quality of the multimedia versions was ranked from 1 to 5 . The lowest quality was marked with 1 and the highest with 5. The Any option was marked with 0 . The user risk attitude value (RV) was computed for each subject.

\section{Flat Rate Billing Plan: Scenario 1}

In the first scenario, the subjects were told that they have a flat rate billing plan. This allows them to use unlimited data without being penalised or limited in any way. This scenario was motivated by the fact that people might not always perceive the highest quality as the best one (Series P n.d.) Therefore, it is necessary to determine first the user preferred multimedia clip quality version. The subjects were presented with the five quality versions of the multimedia clip and they were asked to select one of them. Fig. 2 presents the subjects' preferences towards different multimedia qualities. It can be noticed that most of the people prefer the highest quality $(\sim 57 \%)$, however there are people who also prefer other qualities. There is no statistically significant difference between risk averse and risk seekers answers for a confidence interval of $95 \%(\mathrm{p}=0.22)$. People' preferences were used as a starting point for our evaluation, to determine whether risk averse people would switch to a lower price, hence lower quality version and if the risk averse would prefer to pay for the quality.

\section{Subjects' Multimedia Version Quality Preference for Scenario 1}

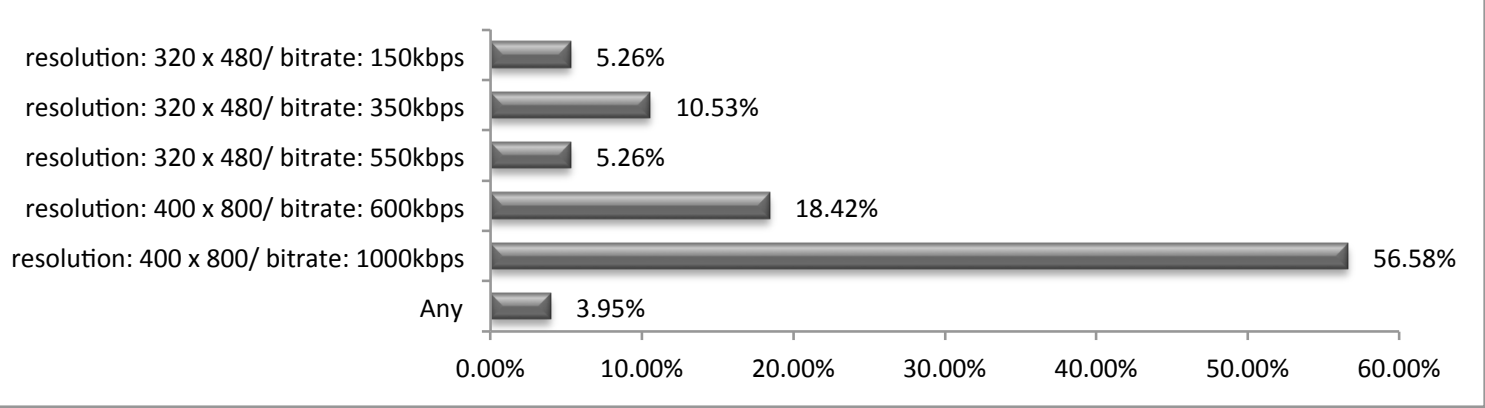

Fig. 2 Subjects Multimedia Quality Preferences for Scenario 1 


\section{Billing Plan 1 - Bundle Data: Scenario 2}

In the second scenario, the subjects were told that they have a bundle of 50MB of data to use for a day. If they exceed the quantity/limit they have to pay $1 € / \mathrm{MB}$. They were told that they have enough data in the bundle to watch any of the above videos, and were asked to select the quality they prefer in this case. The study looked at whether the risk adverse subjects (as classified based on Equation 2) have selected a lower quality than the one selected in Scenario 1 and the risk adverse preferred to remain with the preferred quality. Fig. 3 presents the subjects preference in each case. It can be noticed that although no other cost is incurred by the subjects except for consuming data from the bundle, most risk adverse people $(69.23 \%)$ would prefer to switch to a lower quality and that most risk seekers $(65.15 \%)$ would prefer a better multimedia quality. There is a statistically significant difference between the choices the study participants took in the first scenario both for the risk averse ones $(\mathrm{p}<0.01)$ and risk seekers $(\mathrm{p}<0.01)$ considering a confidence interval of $95 \%$.

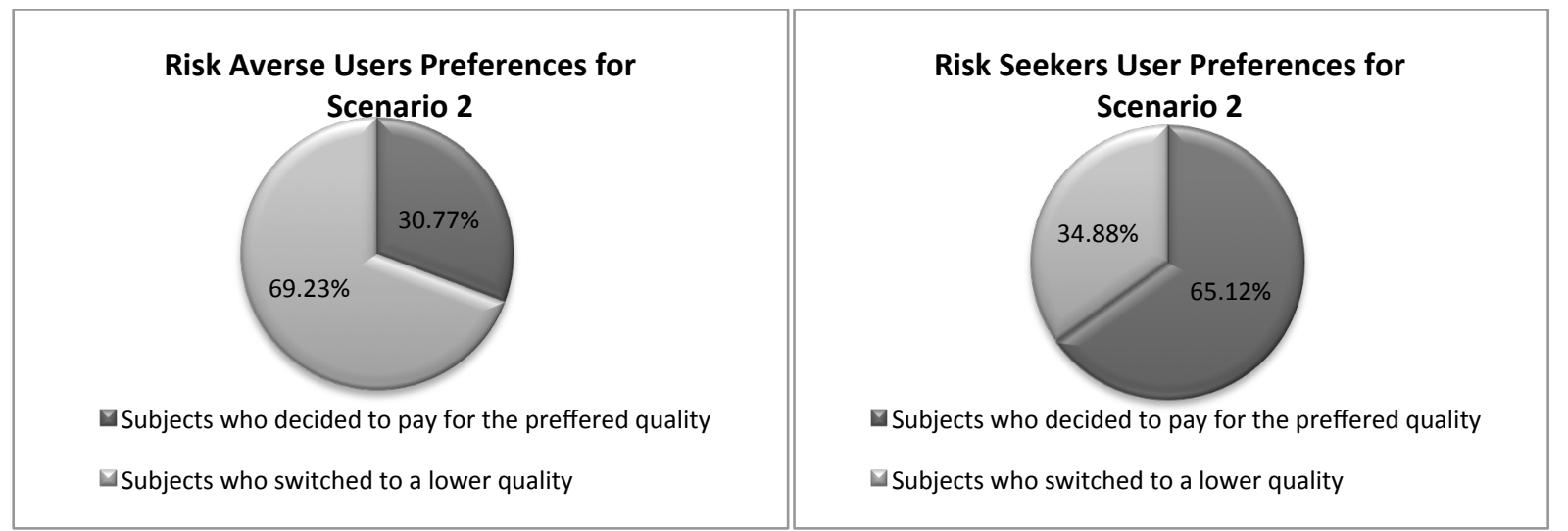

Fig. 3(a) Risk averse subjects preference for Scenario 2; (b) Risk seeker subjects preference for Scenario 2

\section{Billing Plan 1 - Exceeding Bundle Quota: Scenario 3}

For the third scenario, the same data billing plan was used as in Scenario 2. The subjects were told that they have exceeded the bundle data quantity and have to pay $1 € / \mathrm{MB}$. The price they need to pay for accessing each multimedia quality version was also provided to the subjects (see Table 5). As in the previous scenario, the subjects were asked to report their preference. Fig. 4 (a) reports whether risk adverse subjects switched or not for 
a lower quality, and Fig. 4 (b) shows the same information for the risk seekers. We can also notice that most risk adverse users preferred to switch to a lower quality $(68.18 \%)$ and most of the risk seekers preferred to pay for the multimedia quality $(71.90 \%)$. As in the previous case there is a statistically significant difference between the choices the study participants selected in the first scenario both for the risk averse ones $(\mathrm{p}<0.01)$ and risk seekers $(p<0.01)$ considering a confidence interval of $95 \%$.

Table 5. Price to be paid for each multimedia quality version in Scenario 3

\begin{tabular}{|c|c|c|c|c|}
\hline Version & Multimedia Clip Resolution & Multimedia Clip Bit Rate (kbps) & Multimedia Size (MB) & Price \\
\hline 5 & $800 \times 480$ & 1000 & 14 & $€ 14$ \\
\hline 4 & $800 \times 480$ & 600 & 9.15 & $€ 10$ \\
\hline 3 & $480 \times 320$ & 550 & 8.46 & $€ 9$ \\
\hline 2 & $480 \times 320$ & 350 & 5.99 & $€ 6$ \\
\hline 1 & $480 \times 320$ & 150 & 3.65 & $€ 4$ \\
\hline
\end{tabular}

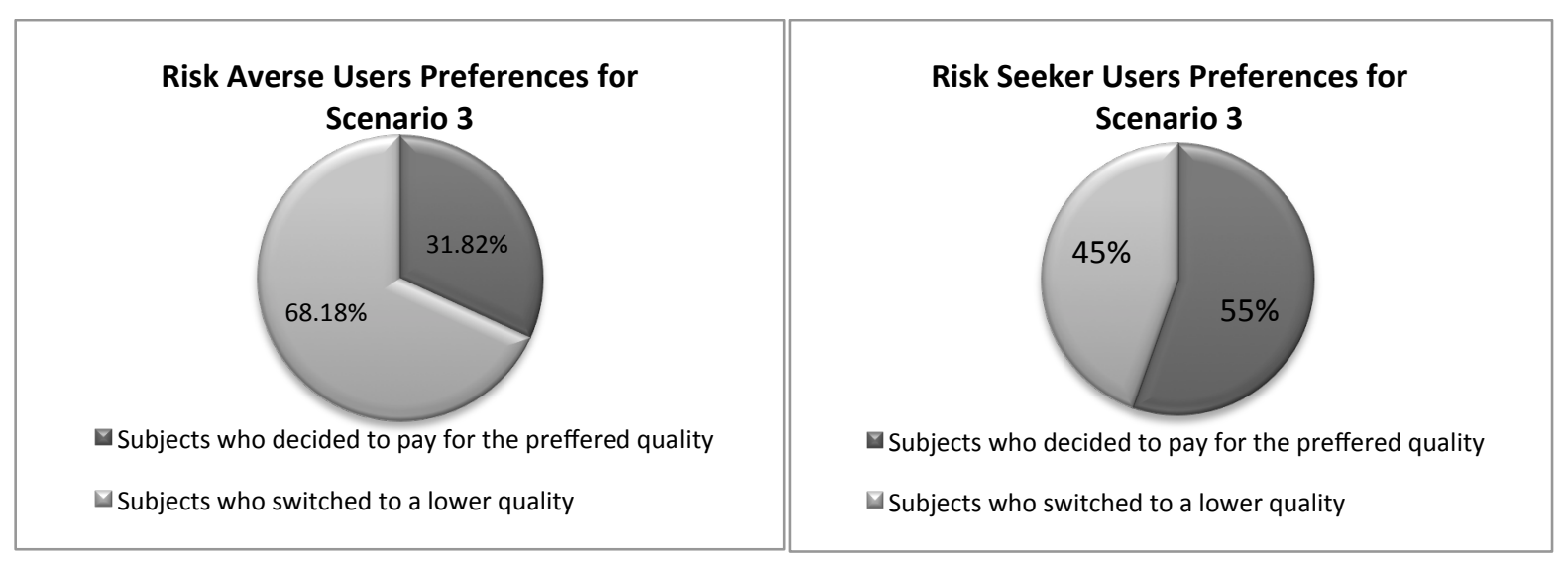

Fig. 4 (a) Risk adverse subjects preference for Scenario 3; (b) Risk seekers subjects preference for Scenario 3 


\section{Billing Plan 2 - Bundle Data: Scenario 4}

Scenario 4 and Scenario 5 make use of the second billing plan. The subjects were told that they have a contract based billing plan, which gives them 500MB per month. In case that they exceed the quantity they will pay $2 \mathrm{c} / \mathrm{MB}$. The subjects were asked to indicate the multimedia version they prefer if they would have enough data in the bundle to download/stream any of the versions without having to pay extra. Fig. 5 presents how people's choices have changed for both risk averse (a) and risk seekers (b). In this case $53.85 \%$ of the risk adverse people preferred to switch to a lower quality. Also, in this scenario, the majority of the risk seekers preferred to pay for the quality $(71.90 \%)$. A possible reason for the higher number of risk averse people preferring to pay for the multimedia quality in this scenario as opposed to the previous one can be that they did not have to pay extra, and even if they would, the cost is very low in this scenario as opposed to the previous one (2c/MB in this scenario, as opposed to $1 € / \mathrm{MB}$ in the previous scenario). A statistically significant difference can be noticed between the choices the study participants made in the first scenario both for the risk averse participants $(\mathrm{p}<0.04)$ and risk seekers participants $(\mathrm{p}<0.01)$ considering a confidence interval of $95 \%$.

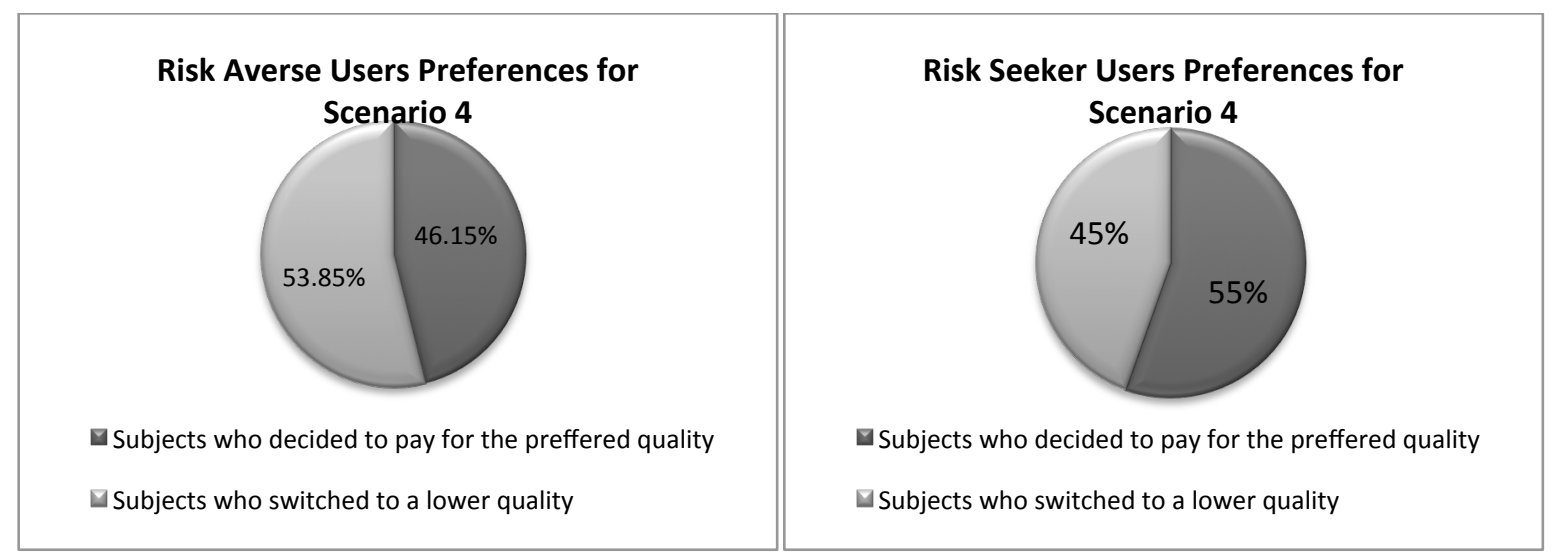

Fig. 5 (a) Risk averse subjects preference for Scenario 4; (b) Risk seekers subjects preference for Scenario 4 


\section{Billing Plan 2 - Exceeding Bundle Quota: Scenario 5}

In the fifth scenario, the subjects were told that they have reached the limit of their bundle (500MB) provided by the billing plan. Therefore, they have to pay extra for accessing the multimedia clip (2c/MB). The cost involved for accessing each multimedia clip version was presented to the subjects (see Table 6). The price in this scenario is far lower than in the previous one. As well as in the previous scenarios, subjects were asked to select one of the multimedia clip versions as their preferred one. Half of the risk seekers preferred to switch to a lower quality even in this case (Fig. 6 (a)). This could be probably explained by the low cost that needs to be paid for the clip versions. The differences between the prices in Scenario 3 and Scenario 5 are highlighted in Figure 7 and it could be noticed that they are far lower than the ones in Scenario 3. In Scenario 5 most of the risk seekers preferred to pay for the multimedia quality $(83.71 \%)$. Even when the price is quite small, the proposed risk model predicts people's choices in the majority of the cases. For a confidence interval of $95 \%$, there is a significant difference between the choices participants made when no cost is involved and in this scenario both for the risk averse participants $(\mathrm{p}<0.01)$ and risk seekers participants $(\mathrm{p}<0.01)$.

Table 6. Price to be paid for each multimedia quality version in Scenario 5

\begin{tabular}{|c|c|c|c|c|}
\hline Version & Multimedia Clip Resolution & Multimedia Clip Bit Rate (kbps) & Multimedia Size (MB) & Price \\
\hline 5 & $800 \times 480$ & 1000 & 14 & $€ 0.48$ \\
\hline 4 & $800 \times 480$ & 600 & 9.15 & $€ 0.20$ \\
\hline 3 & $480 \times 320$ & 550 & 8.46 & $€ 0.18$ \\
\hline 2 & $480 \times 320$ & 550 & 5.99 & $€ 0.12$ \\
\hline 1 & $480 \times 320$ & 150 & 3.65 & $€ 0.08$ \\
\hline
\end{tabular}




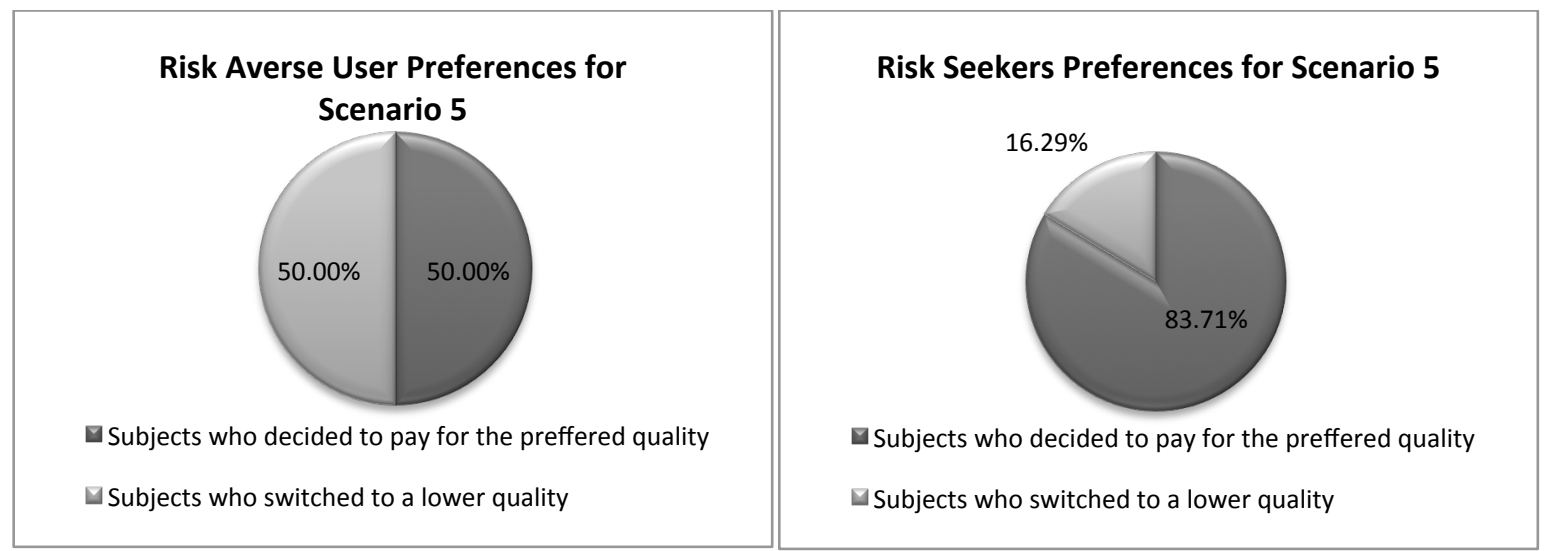

Fig. 6 (a) Risk adverse subjects preference for Scenario 5; (b) Risk seekers subjects preference for Scenario 5

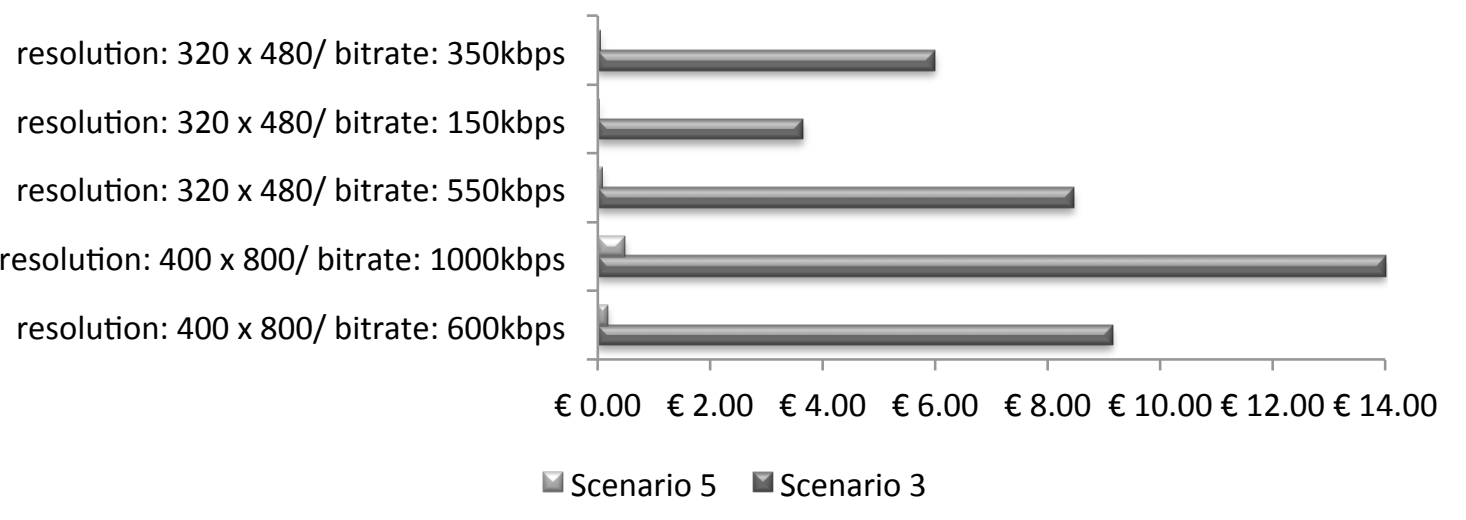

Fig. 7 Cost differences between the scenario 5 and scenario 3 depending on the multimedia quality selected

\section{Billing Plan 3 - Bandwidth Limited: Scenario 6}

The subjects were given the third mobile data-billing plan. As opposed to previous scenarios, after the quantity is exceeded, the user will not have to pay extra but their bandwidth is limited to $64 \mathrm{kbps}$. This would lead to streaming/downloading times as presented in Table 7 and this information was provided to the users. It can be noticed that in this scenario, the model can categorises correctly the risk adverse people as the majority $(84.62 \%)$ of them have selected a lower quality than the preferred one as expressed in Scenario 1 (see Fig. 8). However, the 
results are not that good for risk seekers. Although overall the model prediction is higher than the average, further research needs to be performed to investigate how people's choices vary, when rather than paying a higher price, the bandwidth is limited. A possible reason is that limiting the bandwidth to such a low bit rate, people are limited for their Internet access, hence the risk is higher. As in the previous cases, a statistically significant difference has been obtained for a confidence interval of $95 \%$ for both risk averse participants choices $(p<0.01)$ and risk seekers participants $(\mathrm{p}<0.01)$.

Table 7. Streaming Time for Multimedia Versions

\begin{tabular}{|c|c|c|c|c|}
\hline Version & $\begin{array}{c}\text { Multimedia Clip } \\
\text { Resolution }\end{array}$ & $\begin{array}{l}\text { Multimedia Clip Bit Rate } \\
(\mathrm{kbps})\end{array}$ & Multimedia Size (MB) & Download Time \\
\hline 5 & $800 \times 480$ & 1000 & 14 & 3 minutes and 39 seconds \\
\hline 4 & $800 \times 480$ & 600 & 9.15 & 2 minutes and 23 seconds \\
\hline 3 & $480 \times 320$ & 550 & 8.46 & 2 minutes and 12 seconds \\
\hline 2 & $480 \times 320$ & 550 & 5.99 & 1 minutes and 34 seconds \\
\hline 1 & $480 \times 320$ & 150 & 3.65 & 57 seconds \\
\hline
\end{tabular}

\begin{tabular}{|l||c|c|}
\hline \multicolumn{1}{|c||}{ Risk Averse User Preferences for } \\
Scenarid $\mathbf{6 3 8 \%}$
\end{tabular}

Fig. 8 (a) Risk averse subjects preference for Scenario 6; (b) Risk seekers subjects preference for Scenario 6 


\section{Conclusions}

This research presented a user risk attitude model that takes into account the user's self-assessed risk attitude, the gender, and the age. This model was tested to determine if risk averse people would prefer a lower multimedia quality version when monetary cost is involved compared to the case when no cost is involved, and if risk seekers prefer to pay for their preferred multimedia quality. The model was tested through six scenarios. During these scenarios, the subjects had to select among different multimedia quality options based on different scenarios considering billing plans that exist on the market. The results of the evaluation show that for the proposed user risk model, risk seekers preferred to pay for multimedia quality, whereas risk adverse users preferred to switch to a lower multimedia quality when monetary cost is involved. However, when the mobile data billing plan had the bandwidth limited, rather than a higher price to be paid when the bundle quantity was exceeded, the risk averse people's preference for a lower quality still holds, but it does not show that most of the risk seekers prefer to pay for the multimedia quality. Therefore, according to the tests, the classified risk adverse people selected a lower quality of the multimedia when monetary cost was involved and the risk seekers preferred to pay for it.

\section{Discussions}

Mobile data users, content providers (application service providers, over-the-top providers), mobile network operators and internet service providers could benefit from the results of this research. For mobile data users, the outcome of this research could be beneficial, as they can obtain personalised content based on their needs: the risk averse will get multimedia content that involves low delivery cost and the risk seekers high quality.

From the content providers' point of view, providing personalised content can lead to more satisfied users. It could also reduce the bandwidth consumption and the traffic to the server and/or proxy. When multimedia content is delivered at high quality over an overloaded network, then data loss can occur in the network, affecting the multimedia quality and leading to a poorer user experience than a controlled degradation of the multimedia 
quality by reducing the bit rate (Verscheure et al. 1998). Therefore, providing personalised multimedia content, as proposed in this research, could lead to lower delivery cost and increased revenues for content providers due to better performance and increased customer satisfaction. Cost reductions can be obtained also for the content providers who are paying for the mobile data, by personalising the content and giving incentives for the risk averse users. For example, Amazon is buying mobile data from AT\&T and gets back the investment through selling books and users watching ads on their kindle (Raj et al. 2013). Offering a lower price for risk averse users for watching lower quality video clips could be a part of the marketing strategy.

Mobile Network Operators (MNOs) and Internet Service Providers (ISPs) can also benefit from this research. As the bandwidth is limited and the congestion is a big problem on wireless networks (Trestian et al. 2012), this research can help in reducing the bandwidth consumption, hence diminishing the congestion problem. It can also lead to happier users as they would have personalised content based on their needs, and less congestion to deal with. Reducing the bandwidth consumption could lead to the possibility to acquire more customers and hence increase the revenues. As more bandwidth will be available as a result of this personalisation, MNOs and ISPs could also increase the mobile data bundle size for their customers and hence they could be more competitive. Although 4G networks are offering larger bandwidth, the rate at which mobile data traffic is increasing, having a flat rate plan is not feasible for MNOs (LTE 2012).

As mobile network traffic increases faster than the offered network capacity (Raj et al. 2013) it affects the mobile data users, content providers and network operators. To maintain the quality of service, mobile network operators use various billing plans as a means to avoid congestion (Sen et al. 2013). This affects both content providers and mobile data users. The research proposed in this paper has the potential to alleviate this problem by providing users with personalised content that could help to reduce the content delivery cost for the risk averse users and maintain high video quality for risk seekers. This leads to less bandwidth consumption which has an effect on all three stakeholders, as better quality of service and methods of increasing the revenues for mobile network operators are possible due to bandwidth savings and the possibility to accommodate more users. 
Although this research study has been focused on mobile data plans the results could be applied on any other type of network that makes use of capped billing plans and the content of the delivery cost represents an issue.

\section{Future Work}

There are few factors associated with personality which are used in personalisation (Lekakos \& Giaglis 2006), and the outcome of this research adds to the state of art. For example the outcome of this research can be used to propose mechanisms for adapting multimedia delivery by integrating user risk attitude, to improve both the user experience (by taking into account their preferences), but also optimising the bandwidth that represents a problem on mobile networks (Trestian et al. 2012). Alternatively the mechanism could be adaptable leaving the user the possibility to influence the adaptation (Molnar et al. 2009).

The model could be further improved by increasing the granularity (the general risk question has a risk attitude on a scale from 0 to 10). Currently, the proposed model divides people into two categories: risk adverse and risk seekers. However, a deeper granularity could allow to model people's preferences better. Moreover, the model may be designed to take into account contextual factors that could affect the user decision. One of them consists of differences in the prices the users have to pay (as seen also from our study, the monetary cost influences the decision). The price could vary when the user uses roaming, which is usually quite high or when the user has reached the bundle. Other factors may include how much data from the bundle the people have already consumed, type of content, the necessity for that content to be of high quality, income etc. Further, investigation has to be performed in order to determine how these factors affect people's preferences. Also an investigation should be done whether a similar approach could be used for different media types or a combination of media types. Users' cognitive styles could also have an impact on users' preference towards a certain multimedia quality (Ghinea \& Chen 2008) which has been shown to be mutual dependent with willingness to pay (Ries et al. 2012). Therefore, taking them into account could provide a better modelling of user preferences towards a certain multimedia quality. Moreover, we want to see how risk seekers preferences vary when the bandwidth is limited. 


\section{Acknowledgments}

This work was supported by Irish Research Council for Science, Engineering and Technology.

\section{References}

Albert, A.; 2012. Buyers hit by high mobile data prices, Supply Management. [online]. Source. Available from: http://www.supplymanagement.com/news/2012/buyers-hit-by-high-mobile-data-prices/ [Accessed 27 July 2012].

Apple. 2010. Best Practices for Creating and Deploying HTTP Live Streaming Media for the iPhone and iPad Technical Note TN224, 2010, [online]. Source. Available from: http://developer.apple.com/library/ios/\#technotes/tn2224/ index.html/ [Accessed 27 July 2012].

Bode, K. 2012. AT\&T wages quiet war on grandfathered unlimited users- 2 GB throttle not do subtly pushing users toward meters. Broadband DSL Report. 06 February, 2012., [online]. Source. Available from: http://www.dslreports.com/shownews/ATT-Wages-Quiet-War-onGrandfathered-Unlimited-Users-118235/ [Accessed 27 July 2012].

Borghans, L., Duckworth, A. L., Heckman, J. J., and Ter Weel, B. 2008. The economics and psychology of personality traits. Journal of Human Resources, 43(4), 972-1059.

Brachinger, H. W., Schubert, R., Weber, E. U., Brown, M., and Gysler, M. 1997. Gender differences in risky choice: A theoretical framework and methodological approaches. Working Paper, Institut fuer Wirtschaftsforschung, ETH Zurich.

Breidert, C., Hahsler, M., and Reutterer, T. 2006. A review of methods for measuring willingness-to-pay. Innovative Marketing, 2 (4), 8-32.

Bruke, S.J. 2010. The impact of confidence in evaluating on discounting: A missing information context example. Journal of Consumer Behaviour, 9(5), 33-348.

Bucciol, A., \& Zarri, L. 2013. Financial Risk Aversion and Personal Life History. No. 05/2013. Retrieved September 16, 2013, from: http://leonardo3.dse.univr.it/home/workingpapers/risk_events_BZ.pdf

Caliendo, M., Fossen, F. M., \& Kritikos, A. S. (2009). Risk attitudes of nascent entrepreneurs-New evidence from an experimentally validated survey. Small Business Economics, 32(2), 153-167.

Chetty, M., Banks, R., Bernheim Brush, A.J., Donner, J., and Grinter, R.E. 2012. You're capped' understanding the effects of broadband caps on broadband use in the home, ACM Annual Conference on Human Factors in Computing Systems, 3021-3030, Austin, TX, USA.

Chu, T. 2012. 10 Infographics visualizing digital education. Designbeep. [online]. Source. Available from: http://designbeep.com/2012/06/12/10-infographics-visualizing-digital-education/ [Accessed 08 April 2014].

Cisco. 2012. Cisco visual networking index: Global mobile data traffic forecast update, $2011-2016.14$ February 2012. http://www.cisco.com/en/US/solutions/collateral/ns341/ns525/ns537/ns705/ns827/white_paper_c11-520862.html/ [Accessed 27 July 2012].

Ding, X., Hartog, J., and Sun, Y. 2010. Can we measure individual risk attiudes in a survey? IZA Discussion Paper No 4807. [online]. Source. Available from: http://ftp.iza.org/dp4807.pdf/ [Accessed 08 April 2014].

Dohmen, T., and Falk, A. 2011. Performance pay and multidimensional sorting - productivity, preferences and gender. American Economic Review.101(2), 556-590.

Dohmen, T., Falk, A., David, H., and Sunde, U. 2013. The intergenerational transmission of risk and trust attitudes. indivOxford EconimicPapers. doi: 10.1093/oep/gpt039

Dohmen, T., Falk, A., Huffman, D., Sunde, U., Schupp, J., and Wagner, G. 2011. Individual risk attitudes: measurement, determinants and behavioral consequences. Journal of European Economic Association. 9(3), 522-550.

Dohmen, T., Falk, A., Sunde, U., Schupp, J., and Wagner, G. 2005. Individual risk attitudes: New evidence from a large, representative, experimentally-validated $\begin{array}{llllll} & \end{array}$ http://karlan.yale.edu/fieldexperiments/pdf/falk risk\%5B1\%5D.pdf/ [Accessed 08 April 2014]

Donkers, B., Melenberg, B., and van Soest, A. 2001. Estimating risk attitudes using lotteries, a large sample approach. Journal of Risk and Uncertainty, 22(2), 165-195.

Eckel, C., and Grossman, P. 2007. Men, women and risk aversion: Experimental evidence. C. Plott, \& V. Smith, Handbook of Experimental Economics Results, North-Holland: Elsevier Science. 1(7), 1061-1073.

Falk, A., Becker, A., Dohmen, T., Huffman, D., and Sunde, U. 2013. An experimentally validated preference survey module. CESifo Area Conference on. Behavioural Economics, 25-26 October, Zurich, Switzerland, [online]. Source. Available from: http://www.cesifogroup.de/portal/page/portal/CFP CONF/CFP CONF 2013/Conf-be13-Schmidt/Paper/be13 Sunde.pdf [Accessed 02 March 2014].

Gerpott, T. J. 2009. Biased choice of a mobile telephony tariff type: Exploring usage boundary perceptions as a cognitive cause in choosing between a use-based or a at rate plan. Telematics and Informatics, 26, 167-179.

Ghinea, G. and Chen, S. Y. 2008. Measuring quality of perception in distributed multimedia: Verbalizers vs. imagers. Comput. Hum. Behav. 24, 4 (July 2008), 1317-1329. DOI=10.1016/j.chb.2007.07.013 http://dx.doi.org/10.1016/j.chb.2007.07.013

Grund, C., and Sliwka, D. 2010. Evidence on performance pay and risk aversion. Economics Letters, 106(1), 8-11. 
GSM Arena. [online]. Source. Available from: http://www.gsmarena.com/ [Accessed 08 April 2014]

Guiso, L., Sapienza, P., \& Zingales, L. (2013). Time varying risk aversion. The National Bureau of Economic Research. Available from: http://www.econ.yale.edu/ shiller/behfin/2013_04/Guiso_Sapienza_Zingales.pdf [Accessed 08 April 2014].

Hammitt, J., and Haninger, K. 2010. Valuing fatal risks to children and adults: Effects of disease, latency, and risk aversion. Journal of Risk and Uncertainty, 40(1), 57-83.

Hardeweg, B., Menkhoff, L., and Waibel, H. 2013. Experimentally validated survey evidence on individual risk attitudes in rural Thailand. Economic Development and Cultural Change, 61(4), 859-888.

Harrison, G. W., Lau, M. I., and Rutström, E. E. 2007. Estimating risk attitudes in Denmark: A field experiment*. The Scandinavian Journal of Economics, 109(2), 341-368.

Holt, C. A., and Laury, S. K. 2002. Risk Aversion and Incentive Effects. American Economic Review, 92(5), 1644-1655.

Isomursu, P., Hinman, R., Isomursu, M., and Spasojevic, M. 2007. Metaphors for the mobile Internet. Knowledge, Technology \& Policy, 20(4), 259-268.

ITU-T P.910. (2008). Series P: Telephone Transmission Quality, Telephone Installations, Local Line Networks Available from: http://www.itu.int/rec/dologin pub.asp?lang=e\&id=T-REC-P.910-200804-I!!PDF-E\&type=items [Accessed 08 April 2014].

ITU-T. 2000. IMT-2000 - International mobile telecomunications for the year 200 [online]. Source. Available from: http://www.itu.int/ITUD/imt-2000/DocumentsIMT2000/IMT-2000.pdf [Accessed 11 July 2011].

Jaeger, D. A., Dohmen, T., Falk, A., Huffmann, D., Sunde, U., and Bonin, H. 2010. Direct evidence on risk attitudes and migration. The Review of Economics and Statistics, 92(3), 684-689.

Jeff. 2008. Mobile telephony. [online]. Source. Available from: http://en.kioskea.net/contents/telephonie-mobile/reseauxmobiles.php3[Accessed 23 April 2011].

Lambrecht, A., and Skiera, B. 2006. Paying too much und being happy about it: Existence, causes and consequences of tariff-choice biases. Journal of Marketing Research, 63(3), 212-223.

Lance, W. 2014. iPhone market share shrinks as Android, Windows Phone grow. [online]. Source. Available from: http://www.cnet.com/news/iphone-market-share-shrinks-as-android-windows-phone-grow/ [Accessed 08 April 2014].

Lekakos, G., and Giaglis, G. M. 2006. Improving the prediction accuracy of recommendation algorithms: Approaches anchored on human factors.Interacting with computers, $18(3), 410-431$.

LTE. 2012. LTE outlook. Telecoms. [online]. Source. Available from: http://www.telecoms.com/wpcontent/blogs.dir/1/files/2012/05/OFC_LTEOutlook_May12.pdf/[Accessed 27 July 2012].

Markowitz, H. M. 1959. Portfolio Selection. New York, Wiley.

Middleton, C., and Chang, S. 2008. The adoption of broadband internet in Australia and Canada, in Dwivedi, Y.K., Papazafeiropoulou, A. and Choudrie, J. (eds.), Handbook of Research on Global Diffusion of Broadband Data Transmission, IGI Global, Harrisburg, PA, 818-840.

Mitomo, H., Otsuka, T., and Nakaba, K. 2009. A behavioral economic interpretation of the preference for flat rates: A case of post-paid mobile phone services. Contributions to Economics, 59-73.

MLS. 2010. Flexible learning framework [online]. Source. Available from: http://e-standards.flexiblelearning.net.au/topics/mlearn.html [Accessed 08 April 2014].

Molnar, A., Hava Muntean, C. and Cristea, A.I. 2009. Reusable Quality of Experience aware adaptation strategies for authoring adaptive eLearning, AACE E-Learn World Conference on E-Learning in Corporate, Government, Healthcare, \& Higher Education, 3801-3810, 26-30 October, Vancouver, Canada.

Molnar, A., and Hava Muntean, C. 2010. Educational content delivery: An experimental study assessing student preference for multimedia content when monetary cost is involved, Intelligent Systems Design and Applications, 871-876, Egypt, 2010.

Molnar, A. and Hava Muntean, C. 2011. Mobile learning: An economic approach, Intelligent and Adaptive Learning Systems: Technology Enhanced Support for Learners and Teachers, S. Graf, F. Lin, Kinshuk, and R. McGreal (Eds.), IGI Global, 311-326.

Molnar, A. and Hava Muntean, C. 2013. Cost-oriented adaptive multimedia delivery. IEEE Transactions on Broadcasting, 59(3), 484 - 499.

Nielsen, T., Keil, A., and Zeller, M. 2013. Assessing farmers' risk preferences and their determinants in a marginal upland area of Vietnam: a comparison of multiple elicitation techniques. Agricultural Economics, 44, 255-273.

Nunes, J. 2000. A cognitive model of people's usage estimations. Journal of Marketing Research, 37, 397-409.

Raj, H., Saroiu, S., Wolman, A., and Padhye, J. 2013. Splitting the bill for mobile data with SIMlets. 4th Workshop on Mobile Computing Systems and Applications, Article 1, USA, 2013.

Ries, M., Nemethova, O., and Rupp, M. 2008. On the willingness to pay in relation to delivered quality of mobile video streaming. International Conference on Consumer Electronics, Digest of Technical Papers, 1-2.

Rosen, A. B., Tsai, J. S., and Downs, S. M. 2003. Variations in risk attitude across race, gender and education. Medical Decision Making, 23(6), 511-517. 
Roto, V., Geisler, R., Kaikkonen, A., Popescu, A., and Vartiainen, E. 2006. Data traffic costs and mobile browsing user experience. MobEA IV workshop on Empowering the Mobile Web, in conjunction with WWW2006 conference. Edinburgh. AT \& T Labs Research: [online]. Source. Available from: http://www2.research.att.com/ rjana/MobEA-IV/PAPERS/MobEA IV-Paper 7.pdf/ [Accessed 18 July 2011].

Sackl, A., Egger, S., Zwickl, P., and Reichl, P. 2012. The QoE alchemy: Turning quality into money. Experiences with a refined methodology for the evaluation of willingness-to-pay for service quality. Quality of Multimedia Experience (QoMEX), 170-175.

Sen, S., Joe-Wong, C., Ha, S., Bawa, J., and Chiang, M. (2013). When the price is right: enabling time-dependent pricing of broadband data. SIGCHI Conference on Human Factors in Computing Systems, 2477-2486, France.

Series P: Telephone transmission quality, telephone installations, local line networks. [online]. Source. Available from: http://www.catr.cn/radar/itut/201007/P020100707478901291238.pdf/ [Accessed 27 July 2012].

SOEP. Socio-oekonomisches Panel (SOEP), Daten der Jahre 1984-2009, Version 26.

Taylor, J. W. 1974. The role of risk in consumer behaviour. Journal of Marketing, 38, 54-60.

Train, K. 1991. Optimal regulation: The economic theory of natural monopoly. Cambridge: MIT Press.

Trestian, I., Ranjan, S., Kuzmanovic, A., and Nucci, A. 2012. Taming the mobile data deluge with drop zones, IEEE/ACM Transactions on Networking, 20(4), 1010-1023 doi: 10.1109/TNET.2011.2172952

Traverso, S., Huguenin, K., Trestian, I., Erramilli, V., Laoutaris, N., and Papagiannaki, K. 2012. Tailgate: handling long-tail content with a little help from friends. ACM International Conference on World Wide Web. Lyon, France, 151-160.

Vallina-Rodriguez, N., Erramilli, V., Grunenberger, Y., Gyarmati, L., Laoutaris, N., Stanojevic, R., and Papagiannaki, K. 2012. When David helps Goliath: the case for $3 \mathrm{G}$ onloading. 11th ACM Workshop on Hot Topics in Networks, 85-90.

Verscheure, O., Frossard, P., and Hamdi, M. 1998. MPEG-2 video services over packet networks: Joint effect of encoding rate and data loss on user- oriented QoS, Proceedings of the NOSSDAV 98, Cambridge, England, 257-264.

Webber, E. U. 1999. Who's afraid of a little risk? New evidence for general risk aversion. In Decision Science and Technology, Reflection on the Contributions of Ward Edward, (Eds.) Shanteau, J., Mellers, B. A., Schum, D. A., Kluwer Academic Publisher.

Wowza Media Systems. 2011. [online]. Source. Available from: http:/www.wowzamedia.com/ [Accessed 08 April 2014]. 